\title{
COMPORTAMENTO REPRODUTIVO DE MULHERES INDÍGENAS NO ALTO XINGU, MATO GROSSO, BRASIL: UMA PERSPECTIVA ANTROPOLÓGICA*
}

\author{
Sofia Pereira Madeira**
} Rebeca de Souza e Silva***

\begin{abstract}
Resumo: Os povos indígenas no Brasil sofreram significativa perda populacional no contato com frentes de colonização, alimentando previsões pessimistas que apontavam seu desaparecimento. Entretanto, muitos estão em processo de recuperação demográfica devido à alta fecundidade, fruto de padrões culturais que regulam o tamanho das famílias segundo necessidades de poder e ocupação de territórios, visando o funcionamento de seus complexos sistemas de organização social. Em uma perspectiva antropológica, este artigo procura compreender como aspectos socioculturais delineiam o comportamento sexual e reprodutivo das mulheres indígenas.
\end{abstract}

Palavras-chave: Comportamento reprodutivo. População indígena. Antropologia da saúde. Saúde da mulher.

Reproductive behavior of indigenous women in Alto Xingu, Mato Grosso, Brazil: an anthropological approach

Abstract: The indigenous people in Brazil have experienced significant population loss in the contact with colonization fronts, feeding pessimistic forecasts pointing to their disappearance. However, many indigenous people are in a demographic recovery process due to the high fertility, result of cultural patterns that govern the

\footnotetext{
* Agradecemos à CAPES pela Bolsa de Doutorado, necessária para a realização da pesquisa que originou este artigo.

** Universidade Federal de São Paulo - UNIFESP, São Paulo-SP, Brasil (sofiapmadeira@gmail.com).

*** Universidade Federal de São Paulo - UNIFESP, São Paulo-SP, Brasil (rebecaprev@globo.com).
} 
$|230|$

Comportamento reprodutivo...

size of families according to the needs of power and occupation of the territories, aimed at the functioning of their complex systems of social organization. In an anthropological approach, this article seeks to understand how socio-cultural aspects outline the sexual and reproductive behavior of indigenous women.

Keywords: Reproductive behavior. Indigenous population. Anthropology of health. Women's health.

Comportamiento reproductivo de las mujeres indígenas en el Alto Xingú, Mato Grosso, Brasil: una perspectiva antropológica

Resume: Los pueblos indígenas en Brasil han sufrido significativa pérdida poblacional en el contacto con frentes de colonización, alimentando las previsiones pesimistas que señalaban su desaparición. Sin embargo, muchos están en proceso de recuperación demográfica debido a la alta fecundidad, fruto de patrones culturales que regulan el tamaño de las familias según las necesidades de poder y ocupación de territorios, buscando el funcionamiento de sus complejos sistemas de organización social. En una perspectiva antropológica, este artículo busca entender los aspectos socioculturales que delinean el comportamiento sexual y reproductivo de las mujeres indígenas.

Palabras clave: Comportamiento reproductivo. Población indígena. Antropología de la Salud. Salud de la mujer.

\section{Introdução}

Sabe-se que os povos indígenas no Brasil sofreram severas perdas populacionais em decorrência de epidemias, conflitos, fissões e deslocamentos dos grupos devido ao contato com frentes de expansão econômica, alimentando previsões pessimistas sobre a sobrevivência destes povos. Em estudos pioneiros na área da demografia indígena brasileira, Ribeiro $(1956,1957)$ avaliou o impacto das doenças infecciosas transmitidas aos nativos por ocasião dos contatos com a sociedade envolvente e, tendo em vista os efeitos devastadores destes contatos nas estruturas demográficas e sociais desses povos, o autor supôs que os mesmos entrariam em um processo irreversível de redução populacional, o que provavelmente os levaria à sua completa extinção.

De fato, alguns povos e línguas foram extintos naquele período, porém, estudos mostram que desde o final do século XX muitos povos indígenas no Brasil estão vivenciando um mesmo processo demográfico: o rápido crescimento populacional 
(PAGLIARO et al., 2004). Contudo, o motivo desse acelerado incremento é alvo de importantes questionamentos, até então sem consenso. Azevedo (2006: 55) indaga:

[...] É algo semelhante ao "baby boom" pós-guerras? Ou seja, é um fenômeno de recuperação demográfica ou é uma diferente dinâmica que tem raízes culturais e territoriais? Ou é uma fase temporária que pode acontecer muitas vezes no início da transição demográfica, que se caracteriza por um aumento da população causado pela alta fecundidade e queda da mortalidade?

Entre as várias interpretações possíveis a respeito deste crescimento populacional, há quem a identifique como a segunda etapa do processo de transição demográfica, chamada de "revolução demográfica" (LANDRY 1982 apud ERVITTI DIAZ, 1998), explicada a seguir.

\section{Dinâmica Demográfica dos Povos Indígenas: algumas interpretações}

Segundo Thompson (1929), o processo de transição pressupõe quatro etapas pelas quais uma sociedade com elevados níveis de natalidade e mortalidade passa até alcançar baixos valores destas variáveis. Inicialmente, num período pré-moderno, as taxas de natalidade e mortalidade são elevadas e a população sofre constantes oscilações devido à sua vulnerabilidade perante epidemias e eventos naturais como seca e dilúvios. A transição teria início com a queda da mortalidade, proporcionada por melhorias nas condições de saneamento básico e saúde, configurando uma fase intermediária com mortalidade decrescente enquanto a natalidade aumenta ou permanece elevada, provocando um rápido incremento demográfico. Posteriormente, com a urbanização, industrialização e o maior acesso aos métodos contraceptivos modernos, a fecundidade entraria em queda, reduzindo as 
taxas de natalidade e favorecendo a estabilidade da população. Finalmente, numa etapa pós-moderna, os níveis da natalidade caem abaixo do nível de reposição ${ }^{1}$ e, paralelamente ao já baixo nível de mortalidade, a população tende a envelhecer e entrar em declínio (THOMPSON, 1929).

De fato, as populações indígenas em processo de crescimento populacional apresentam atualmente uma mortalidade moderada, normalmente em queda, e altas taxas de natalidade - cenário compatível com a fase intermediária do processo de transição demográfica -, equação que resulta em rápido aumento populacional. No entanto, muitas são as críticas em torno da teoria da transição demográfica, uma vez que esta pressupõe um processo linear, universal e unidirecional no tocante às transformações das variáveis mortalidade e natalidade.

Em estudos sobre a transição demográfica na América Latina, Guzmán et al. (2006) identificaram diferentes etapas neste processo e a alteração da sequência em que os eventos ocorrem. A teoria da transição demográfica pressupõe a queda da mortalidade e a subsequente queda da fecundidade, tendo impactos positivos na expectativa de vida ao nascer e no declínio da taxa de crescimento natural da população. Porém, tanto a queda da mortalidade quanto da fecundidade ocorreram de modo muito distinto entre os países da América Latina e do Caribe, sendo necessário pensar em "transições" demográficas.

\footnotetext{
${ }^{1}$ Define-se nível de reposição como o nível de fecundidade de um grupo de mulheres que têm um número de filhos suficientes para repor a si mesmas e aos seus cônjuges. Teoricamente, esse nível é de 2,1 filhos por mulher, ou seja, uma vez alcançado esse nível os nascimentos atingem o equilíbrio com as mortes e, na ausência de imigração e emigração, a população parará de crescer e se tornará estacionária. Quando o nível de fecundidade é maior que 2,1, a população tende a crescer e, quando a fecundidade está abaixo deste nível, a população diminui - na ausência de migração (SANTOS; LEVY; SZMRECSÁNYI, 1980).
} 
Na América Latina, a transição da fecundidade não foi egulada pela nupcialidade, como ocorreu nos países europeus com o adiamento dos casamentos e o aumento do número de mulheres solteiras nas idades adultas. Na região latina e caribenha, diferentemente do restante do mundo, o início da transição se deu com o aumento da fecundidade e da proporção de casamentos entre 1950 e 1960, simultaneamente à queda da mortalidade. A nupcialidade passou a ocorrer mais precocemente e a fecundidade permanecia elevada, o que, somado à rápida queda da mortalidade, fez com que a taxa de crescimento atingisse 3\% ao ano no decênio 1950-1960. A queda da fecundidade ocorreu por múltiplas causas e em velocidades distintas entre os vários países do mundo, contudo, a informação e o acesso aos métodos contraceptivos eficazes (sobretudo a esterilização feminina e a pílula) fizeram com que a fecundidade das mulheres latinoamericanas fosse mais facilmente controlada.

Os autores concluem que as variações nos processos de transição demográfica entre os países latino-americanos e caribenhos se devem aos fatos originários de sua cultura e história, como a colonização, o regime político e econômico de escravidão e monocultura, o genocídio de uma significativa parcela das populações indígenas e a imposição etnocêntrica de padrões culturais, além do desigual processo de modernização observado na região - o que reforça a hipótese da ocorrência de diversas e distintas transições demográficas (PATARRA; OLIVEIRA, 1988).

Nessa perspectiva, muitas são as críticas à teoria da transição demográfica, tal como foi formulada por Thompson (1929) e defendida por Notestein (1945), apontando que esta não leva em consideração a diferença no patamar inicial e final das funções mortalidade e fecundidade vivenciado por distintas sociedades, tampouco explica as diferentes intensidades e velocidades deste processo (PATARRA; FERREIRA, 1986; PATARRA; OLIVEIRA, 1988; GOLDANI, 1985; CHESNAIS, 1992; SOUZA, 2008). As etapas sugeridas nesse modelo teórico configuram-se como previsões estendidas a todas as populações do mundo, mas se baseiam em eventos ocorridos em países desenvolvidos da Europa Ocidental e 
| 234 |

Comportamento reprodutivo...

nos Estados Unidos. Ademais, a teoria é formulada como se todos os povos desejassem e/ou devessem alcançar um mesmo padrão de comportamento reprodutivo, se esquivando de ponderar importantes questões históricas e culturais que antecedem e modelam as condutas demográficas. Enfim, essa teoria reluta:

\begin{abstract}
[...] em reconhecer o significado de baixas ou altas taxas de crescimento populacional como parte de um longo processo histórico e enquanto um produto de uma ampla diversidade de sistemas socioeconômico e cultural, ou seja, a dificuldade de se associar, em uma perspectiva temporal longa, os níveis e tendências demográficas às dimensões explicativas no contexto social em que se processam (SOUZA, 2008: 18).
\end{abstract}

Vários foram os esforços para encontrar modelos teóricos explicativos que abrangessem um grande número de realidades sociodemográficas, encontrando semelhanças e repetições que pudessem sustentar teorias pautadas, principalmente, no comportamento demográfico e no desenvolvimento socioeconômico das populações. Em uma abordagem cultural, Lorimer (1958) ressalta os valores e práticas reprodutivas como parte da estrutura social, relacionadas aos sistemas de organização interna de cada sociedade.

$\mathrm{Na}$ interface entre demografia e antropologia, Zubrow (1976) buscou o entendimento do comportamento demográfico e reprodutivo em relação a algumas variáveis culturais. $\mathrm{O}$ autor chegou a resultados polêmicos e antropologicamente questionáveis, anunciando máximas de teor determinista como: "a fecundidade é função direta da demanda por trabalho e da demanda da família por capital"; "a fecundidade é diretamente relacionada com o casamento", isto é, à frequência dos casamentos, idade ao casar, frequência dos intercursos sexuais e concepção; entre outras. Entretanto, sabe-se que em muitos casos essas equações não se aplicam, questionando a generalidade destas conclusões.

Em 1929, com a apresentação da teoria da transição demográfica desenvolvida por Warren Thompson (1887-1973), os 
estudos que procuravam relacionar o comportamento reprodutivo das sociedades à sua organização sociocultural ganham fôlego, como a pesquisa desenvolvida por Caldwell (1975) no Oeste da África. Neste estudo, constatou-se que sociedades tradicionais daquela região mantinham formas deliberadas de controle da sua reprodução (concepção e natalidade), sobretudo com o espaçamento entre os partos através do tabu pós-parto, que sugere a abstinência sexual dos pais da criança até que a mesma se aproxime de completar 1 ano de idade.

Pagliaro (2002b) também chama atenção para o fato de que a manutenção ou mesmo a elevação das taxas de fecundidade das populações indígenas não decorrem necessária e exclusivamente de melhorias nas condições de vida e saúde desses povos, sendo possivelmente fruto de "padrões reprodutivos ancestrais" que, segundo a autora:

[...] são compatíveis com seus anseios e necessidades estratégicas de poder e ocupação de território [uma vez que] os povos indígenas podem ter domínio sobre o tamanho de família e de população que desejam para atender às necessidades inerentes ao funcionamento de seus diferentes e complexos sistemas de organização social (PAGLIARO, 2002a: 2).

A autora afirma que, para alcançarem desejados níveis de natalidade, as sociedades indígenas lançam mão de práticas deliberadas de controle dos nascimentos como o tabu pós-parto (com restrições às práticas sexuais num determinado intervalo de tempo após o nascimento da (riança) ${ }^{2}$, o uso de ervas anticoncepcionais de efeito temporário ou permanente, a realização

\footnotetext{
${ }^{2}$ Nos trabalhos de campo realizados no Alto Xingu pôde-se observar que o longo período de abstinência sexual dos pais no período pós-parto - que perdura até que a criança comece a engatinhar ou andar - e o prolongado período de amamentação (de aproximadamente dois anos) provocam um significativo espaçamento entre os filhos, o que acaba por interferir diretamente no nível de fecundidade das mulheres do Alto Xingu.
} 
|236 |

Comportamento reprodutivo...

de abortos por meio de ingestão de substâncias químicas ou ações mecânicas e ainda práticas tardias de controle da fecundidade.

Vale citar a pesquisa de Lopez (2000) junto à comunidade Guarani Mbyá de Paraty/RJ, que encontrou um elevado nível de fecundidade que, segundo a autora, está intimamente relacionado à estrutura sociocultural Guarani, devido ao interesse e à necessidade do grupo de se manter numérica, econômica e culturalmente, sugerindo um comportamento reprodutivo intencional.

Nesse sentido, as hipóteses atuais sobre a relação entre fecundidade e cultura/organização social se pautam na premissa de que "a fecundidade é produzida por um sistema social e cultural; as explicações sobre as mudanças no nível da fecundidade têm, portanto, que ser estruturais" (AZEVEDO, 2003: 14). Ainda segundo AZEVEDO (2003: 13):

\begin{abstract}
Antropólogos já demonstraram que muitas sociedades primitivas com numerosas instituições, crenças, códigos simbólicos, tabus, formam uma máquina bem integrada onde cada elemento tem várias funções no controle da reprodução humana. Historiadores e demógrafos demonstraram que na Europa pré-revolução industrial, muitos mecanismos operavam nas sociedades durante vários séculos com regularidade controlando os parâmetros demográficos de acordo com seus recursos e tecnologias.
\end{abstract}

Pode-se dizer que os aspectos centrais da cultura - como estruturas sociais, sistemas políticos, rituais e cosmologias -, juntamente com aspectos históricos e ambientais vivenciados pelos povos indígenas produzirão distintas dinâmicas demográficas entre eles, sendo preciso reconhecer os fatores que contribuem para a configuração de cada perfil populacional existente.

Tal constatação corrobora a importância e a crescente necessidade da realização de estudos que visem à compreensão do comportamento sexual e reprodutivo dos povos indígenas, 
interpretado à luz de conhecimentos sobre sua estrutura cultural e dinâmica demográfica.

\section{Metodologia}

$\mathrm{Na}$ pesquisa que originou este artigo, teoria e prática demográficas somam-se a uma bagagem antropológica e, juntas, levam ao desafio de compreender o comportamento sexual e reprodutivo de mulheres indígenas de determinada etnia localizada no Alto Xingu, cuja identidade é preservada por questões éticas referentes ao conhecimento da continuidade de práticas de controle da natalidade, comumente julgadas sob a óptica e a moral cristãs.

Diferentemente da metodologia adotada pela Antropologia até o século XIX, na qual sobressaía a idéia de queum distanciamento entre antropólogos e nativos ampliaria a cientificidade da pesquisa, pressupondo que as sociedades tribais eram inferiores e encontravam-se em processo de "evolução", o trabalho de campo, largamente utilizado pela antropologia moderna, aproxima o pesquisador da realidade do grupo pesquisado, ultrapassando a mera observação e favorecendo a efetiva participação do antropólogo nas relações cotidianas estabelecidas no interior do grupo. Assim ressaltou Brandão (1984: 11):

\footnotetext{
Quando Malinowski [sic] desembarcou nas ilhas de Trobriand, não era apenas um método que ia ser reinventado ali: era uma atitude. Não mais reconstruir a explicação da sociedade e da cultura do "outro" através de fragmentos de relatos de viajantes e missionários. Ir conviver com o outro no seu mundo, aprender a sua língua, viver sua vida, pensar através de sua lógica, sentir com ele.
}

Essa metodologia foi denominada observação participante e assume uma postura ideológica contrária à possibilidade de se conhecer em profundidade algum aspecto da vida de 
| 238 |

Comportamento reprodutivo...

determinada sociedade ou cultura sem um efetivo envolvimento entre o pesquisador e aquilo ou aquele que é investigado. Essa prática metodológica vai de encontro à idéia que vigorou durante décadas de que a adoção de uma postura objetiva, de afastamento e neutralidade - por parte do pesquisador - garantiria a cientificidade dos dados colhidos, pautada na hipótese de que "[...] uma metodologia científica adequada serve para proteger o sujeito de si próprio, de sua própria pessoa, ou seja: de sua subjetividade" (BRANDÃO, 1984: 7).

Ao contrário do que sustentavam diversas correntes antropológicas, essa metodologia pressupõe a inviabilidade de uma postura "neutra", depositando no contato e no convívio a possibilidade de se conhecer de fato o universo do outro. É através da observação participante que o antropólogo tem a oportunidade de vivenciar e conhecer as variadas dimensões da vida social do grupo no qual se insere. O pesquisador pode observar e posteriormente interpretar fatos cotidianos do grupo, sejam manifestações cerimoniais ou acontecimentos corriqueiros como o cuidado com as crianças, o trato dos animais, a produção de alimentos, a distribuição dos bens, os rituais, os diálogos, as brincadeiras, os gestos, enfim, as diversas facetas do 'outro' que se revelam aos olhos atentos de um bom observador, entre uma palavra e outra ou no mais denunciante silêncio. Como já observara Malinowski (1990):

Logo depois que me instalei em Omarakana (Ilhas Trobriand), comecei, de certa forma, a tomar parte na vida da aldeia, a buscar quais os acontecimentos importantes ou festivos, a adquirir um interesse pessoal no diz-que-diz e no desenrolar dos acontecimentos da pequena aldeia. [...] Durante o meu passeio matinal pela aldeia, podia observar os mínimos detalhes da vida familiar, a higiene, a cozinha, as refeições; podia ver os preparativos para o dia de trabalho, as pessoas saindo para atender aos seus interesses [...]. Disputas, piadas, cenas familiares, eventos usualmente triviais, às vezes dramáticos, mas sempre significativos, formavam a atmosfera de minha vida diária, assim 
como da deles. [...] Mais tarde, no correr do dia, o que quer que acontecesse seria facilmente acessível; não havia qualquer possibilidade de que escapasse à minha observação.

Partindo desta postura metodológica, a pesquisa se deu em alguns períodos de trabalho de campo realizados em 2013 na aldeia do povo estudado, ao sul do Parque do Xingu. Através de levantamentos de dados quantitativos e qualitativos construiu-se um banco de caráter primário, a partir do qual se buscou responder aos questionamentos iniciais desta pesquisa.

Para coletar os dados foram feitas visitas domiciliares e reuniões com grupos de mulheres, coletando-se dados censitários da comunidade e dialogando com as mulheres do grupo sobre questões reprodutivas. As conversas se deram na língua portuguesa, apesar de algumas mulheres não dominarem o idioma - diferentemente dos homens que, por acessar frequentemente as cidades, acabam dominando a língua. Por essa razão, em alguns momentos recorremos a outras mulheres da família para traduzir a fala das mulheres mais velhas, por exemplo, que não falam português.

Nesta pesquisa, o intervalo etário estipulado para o período reprodutivo da mulher é diferente daquele sugerido para grupos nãoindígenas-de 15 a 49 anos-, tendo seu início mais precocemente, aos 12 anos. Isso se justifica pelo fato de ser comum entre diversos povos indígenas a vida sexual e reprodutiva da mulher ter início antes dos 15 anos, sendo possível encontrar mulheres que, aos 12 anos, já tenham iniciado sua história reprodutiva (PAGLIARO, 2002a; AZEVEDO, 2003). Inúmeros pesquisadores da saúde indígena trabalham com o intervalo em questão e seu uso tem se mostrado pertinente, motivo pelo qual as idades entre 12 e 14 anos foram incluídas no período reprodutivo desta pesquisa. Excluíramse as idades de 10 e 11 anos por ser insignificante o número de mulheres nestas idades com vida sexual ativa ou filhos.

Apesar de terem ultrapassado o teto etário proposto para o intervalo reprodutivo, algumas mulheres acima de 50 anos foram 
| 240 |

Comportamento reprodutivo...

ouvidas e seus depoimentos foram de inestimável importância para este estudo.

\section{Processos rituais: ser e tornar-se mulher}

Culturalmente, há uma rede de cuidados que visam garantir que os indivíduos envolvidos em processos de nascimento, amadurecimento, adoecimento ou morte possam concluir estes ciclos com o menor risco possível. Segundo Van Gennep (1977: 26), "toda alteração na situação de um indivíduo implica ações e reações que devem ser regulamentadas e vigiadas, a fim de a sociedade geral não sofrer nenhum constrangimento ou dano".

O simples fato de viver exige passagens sucessivas de uma sociedade à outra ou de uma situação social à outra de modo que a vida individual consiste em uma sucessão de etapas, tendo por começo e término conjuntos da mesma natureza - a saber, nascimento, puberdade, casamento, maternidade/paternidade, progressão de idade, de classe, ocupação, iniciação nas sociedades religiosas e morte.

A vivência e a transposição destas etapas são regidas por processos rituais que atuam na construção dos indivíduos e das coletividades. Segundo Viveiros de Castro (1987), essa construção é um processo de formação física, espiritual e social da pessoa, pelo qual todos devem passar a fim de tomar posse de um novo "papel social", que lhes acrescentará novas obrigações e responsabilidades no interior do grupo. Esses processos não são encarados como um momento natural, independentes da intervenção humana - embora se manifestem em eventos de natureza obrigatória -, mas ao inverso disso, precisam ser acompanhados de perto pelos adultos do grupo, cujas intervenções garantem o êxito da transição do estado inicial para o estado final.

Turner (1974) interpreta os ritos de passagem como processos rituais necessários à modelagem do ser "transitante", uma vez que os indivíduos envolvidos nesses processos parecem "[...] reduzidos 
ou oprimidos até uma condição uniforme, para serem modelados de novo e dotados de outros poderes, para se capacitarem a enfrentar sua nova situação de vida" (TURNER, 1974: 118).

No caso feminino, é a primeira menstruação (menarca) que rompe a infância e insere a jovem entre o "ser" e o "tornarse" mulher, processo que constitui o ritual feminino de passagem. Viveiros de Castro (1987) toma o ritual de reclusão pubertária feminina como parte da construção da pessoa xinguana, por meio da fabricação do corpo e aprendizagem de saberes de domínio adulto - ambas igualmente necessárias à vivência em grupo. Segundo o autor, a transição social é uma mudança corporal "vergonhosa", daí a necessidade do isolamento social da reclusa, cujo comportamento é limitado ao silêncio e à "invisibilidade" Após um período de isolamento, a jovem toma posse de seu novo "papel social" e assume sua posição no interior do grupo.

Shorter (1989) entende a menarca como um acontecimento sentido fisicamente pela mulher antes de se tornar consciente: "somente mais tarde é que o significado se torna manifesto de maneira a dar sentido individual ao que é, de início, um evento desconcertante e privado" (SHORTER, 1989: 71). Ainda segundo a autora:
Menstruação, casamento, gravidez e menopausa, acham-se todos envolvidos na efetivação do significado, não simplesmente na expressão deste. A mudança chega a uma mulher, é recebida e registrada inicialmente no corpo; somente depois é que o significado se revela. O que o ritual lhe revela, consciente e inconscientemente, é o que antes permanecera oculto, mas está agora pronto para ser desvelado. Depois, ela não mais o conhece parcialmente ou por ouvir dizer, mas por verificação

\footnotetext{
${ }^{3}$ Segundo Viveiros de Castro (1987), o ser em "fabricação" está nu, não usa pinturas nem adornos - característicos de "estados", ou seja, posições sociais. Uma vez desprovido de posição social, restam-lhe o isolamento e a clausura a fim de completar o seu processo de formação.
} 
| 242 |

Comportamento reprodutivo...

própria de sua psique ou alma. [...] Agora como então, a mulher descobre o uso correto de seu corpo modificado, que é o mesmo que descobrir sua lei e o significado dela. O objetivo e a intenção inconscientes do chamado à mudança são então atendidos. [...] Ela cresceu (SHORTER, 1989: 85-86).

Embora a autora não faça a distinção feita por Van Gennep (1977) entre puberdade fisiológica e social - que não se trará tratada aqui -, pode-se concluir que a puberdade fisiológica - neste caso, anunciada pela subtaneidade da menarca - desencadeará a puberdade social, ou seja, revelará para o grupo as transformações sentidas individualmente pelo corpo feminino, constituindo "[...] uma tentativa de ajustar e restabelecer a si mesma [perante um] corpo alterado e um espírito confrontado" (SHORTER, 1989: 81). Com a passagem da infância à mocidade, a menina sofre a perda ou mudança, sua morte e renascimento, sentindo-se irrevogavelmente separada da infância. Conforme Shorter (1989: 70):

Com ou sem o benefício do ritual, uma garota é naturalmente impelida ao estado de mulher no começo da menstruação. Para ela, isso assinala a saída da infância e o ingresso no estado adulto. É um rite de passage entre nascer mulher e tornar-se mulher. Conscientemente ou não, no espaço intermediário entre dois mundos, o da criança e o do adulto, uma menina/ mulher prepara-se para ser a pessoa que física e também espiritualmente será. Contudo, independente do quanto aprenda do estado do seu ser na ocasião, a jornada para a frente e o caminho do próximo estágio de sua vida continuam. Ela não pode demorar-se no limiar; seu corpo garante isso.

O processo ritual de iniciação, portanto, impede que as transformações no corpo da moça ocorram sem o acompanhamento de um ordenado sistema simbólico, uma vez que "o ritual, por si, não garante uma passagem segura, mas lhe garante significado" (SHORTER, 1989: 67). Assim, é papel da iniciação feminina 
exteriorizar, acompanhar e agregar significados às mudanças de natureza corpórea para a apresentação simbólica e social de uma nova mulher.

O ritual feminino de iniciação seria, portanto, o momento social que revela tanto a distinção quanto a separação entre o mundo da infância e o mundo adulto, ou seja, aponta muito mais que as mudanças dadas pela maturação fisiológica do corpo feminino. Através do processo ritual, a mulher toma consciência destas transformações e toma posse de um novo corpo, agora maduro, adulto, feminino e fecundo, sendo apresentada como mulher, passível de pretendentes e propostas de casamento.

De posse deste corpo maduro e de um novo papel social, a mulher segue atravessando processos rituais relacionados a eventos como casamento, gravidez, pós-parto, luto, iniciação em pajelança, adoecimento e morte, sendo acompanhada de perto por outras mulheres e pela comunidade. A semelhança entre estas tantas cerimônias rituais reside em seu objetivo final e nos meios quase idênticos para atingí-lo. O objetivo é fazer um indivíduo passar de uma situação a outra, assistindo material e espiritualmente a este processo, partindo do pressuposto de que cada um tem atrás de si várias etapas, tendo atravessado diversas fronteiras.

A gravidez, assim como outros eventos do ciclo vital, não é um processo completamente individual, podendo atingir positiva ou negativamente toda a comunidade. Questões espirituais relativas à má sorte e ao feitiço assombram a comunidade e põem em risco o equilíbrio e a ordem social. Condutas que aparentemente são privadas na verdade respondem a um conjunto de normas e preceitos definidos coletivamente segundo o contexto social, cultural, político e econômico do grupo.

\section{Comportamento reprodutivo: saberes e práticas}

Pela expressão "passar mês" as indígenas do grupo estudado se referem em português ao mês em que não se tem fluxo 
menstrual, aumentando a desconfiança de uma possível gravidez. A confirmação vem em seguida e, segundo elas, os sintomas são os mesmos: a mulher fica sem fome, sem vontade de comer peixe, sento enjôos, tem alterações de humor e de ânimo. Nos dizeres de uma delas: "[...] o cheiro do fogo dá dor de cabeça, é como se a mulher estivesse doente, só quer ficar na rede". Entre elas, diz-se que os sintomas de gravidez de menina são mais amenos, já quando a gravidez é de um menino, a mulher sofre mais e parece doente, "[...] fica deitada na rede, sem querer comer a comida típica, querendo a comida da cidade, que é diferente".

Quanto à alimentação há restrições da gravidez ao pósparto, se estendendo ao pai da criança, que tem limitações na alimentação e tarefas diárias. A mulher fica proibida de comer vários itens da culinária local como tartaruga e macaco, ambos pelo receio de má formação no bebê, que pode nascer com dedos dos pés e mãos colados ou sem as mãos. O mesmo receio impede que gestantes comam macaúba, evitando que o bebê nasça com bolinhas semelhantes às sementes da fruta espalhadas pelo corpo.

O tracajá, importante alimento da dieta local, só pode ser comido após dois ou três meses de gravidez, quando os pés e as mãos do bebê já estiverem formados. E depois de comer o tracajá a mulher precisa esfregar os dedos para garantir que o "defeito" dos dedos dos tracajás não "pegue" no bebê.

Durante toda a gravidez o mel é proibido, pois, segundo informantes, provoca erupções e prurido na pele do bebê e, em casos mais graves, feridas na cabeça da criança. Esta restrição se estende até o pós-parto e vale para as mães e bebês de colo, sendo liberada depois que o bebê andar. Também é proibido comer cará, um tubérculo semelhante à batata, porque cria uma deformação perto da genitália do bebê.

Os peixes disponíveis na região são variados e têm restrições diferentes. O peixe cascudinho é proibido na gravidez toda, assim como o peixe "pretinho" que, se ingerido, provoca a má formação do peitoral do bebê, que nasce afundado como o peito do próprio 
peixe. Já o peixe cachorra pode ser comido durante toda a gravidez, mas é proibido no pós-parto sob a suspeita de causar diarréia e até mesmo a morte da criança, pois, segundo uma informante, "o peixe cachorra mata a criança de susto porque esse peixe é um bicho ${ }^{4 "}$.

O pequi e o beiju - alimentos centrais da culinária altoxinguana - são permitidos durante toda a gravidez e puerpério. Eles são oferecidos às crianças assim que acaba o aleitamento materno exclusivo, sendo comum ver crianças que já se alimentam de beiju, peixe e mingau de pequi seguirem mamando no peito - prática que costuma se estender até os dois anos de idade da criança.

No início da gravidez, quando o bebê "está pegando", os trabalhos artesanais são atividades proibidas tanto para a mãe quanto para o pai, que não pode confeccionar bancos nem máscaras, sobretudo objetos com alusões a animais. Segundo uma mãe, "uma vez o pai fez um banco de jacaré e o bebê nasceu com cabeça de jacaré. Também não pode colar coisas, cadeira, por exemplo, senão o bebê nasce com a orelha colada ou outra parte do corpo".

A participação em danças e cerimônias rituais também sofre restrição no período da gravidez, sendo permitido à gestante dançar e se pintar apenas até o início da gravidez. “Quando aparece a barriga, não pinta mais", segundo uma informante.

No momento do parto, não é comum a mulher gritar nem reclamar de dor. Dizem as mulheres locais que, ao invés de gritar, é preciso fazer força. O parto pode acontecer com a mulher deitada na rede - põe-se a rede bem baixa, a parturiente senta voltada para a lateral da rede, apóia os pés no chão e as mãos no apoiador - ou a

${ }^{4}$ Para os povos do Alto Xingu, os elementos da natureza como animais, plantas, terra, fogo, água e ar são dotados de espiritualidade, chamados "mamaés". Os espíritos da natureza estão em constante contato e interação com a comunidade, relação delicada que preserva o equilíbrio da vida. As doenças, os feitiços e as rupturas de tabus e regras sociais colocam em risco esta harmonia, podendo trazer malefícios para toda a comunidade. A expressão "bicho" utilizada na fala citada se refere ao caráter perigoso de um possível confronto com a entidade que habita os peixes. 
mulher fica de fora da rede, de cócoras, com as mãos apoiadas em duas redes dispostas uma de cada lado do seu corpo.

Segundo as informantes, toda grávida faz acompanhamento com a equipe médica no Pólo Leonardo (pólo ao sul do Parque), mas o número de exames depende do pré-natal e da disponibilidade da gestante em seguir a conduta médica. Geralmente, se o parto está demorando, os agentes indígenas de saúde chamam uma enfermeira pelo rádio 5 . Segundo informantes, a maioria das mulheres continua parindo na aldeia, mas enfermeiras e auxiliares do Pólo Leonardo se deslocam com frequência para acompanhar os partos.

Geralmente, a parteira é uma parenta ou conhecida da família, pois o parto é considerado um momento íntimo e feminino, restrito às mulheres mais próximas e experientes. Aos homens não é proibida a participação, mas diz-se frequentemente que permanece naquele ambiente "só quem tem coragem" porque, segundo os altoxinguanos, o sangue da mulher enfraquece e debilita o homem, deixando-o doente e com má sorte na caça e na pesca. Quando a mulher está menstruada, é comum que os homens se distanciem, evitando relações sexuais e até mesmo beber mingau da mesma panela que ela. Isso se explica "[...] devido à qualidade 'impura' tanto da mulher em si mesma quanto do sangue menstrual" (VAN GENNEP, 1977: 73). Como ressalta Shorter (1989: 76), "o sangue é um símbolo natural de ferida, sacrifício e martírio".

Entre as mulheres mais experientes estão as chamadas "raizeiras", que dominam conhecimentos sobre as plantas e seus poderes medicinais. Conhecendo o poder das ervas, elas regulam doses e frequência com que as mulheres devem tomar os chás que preparam. Segundo uma informante: "a raizeira já traz o chá pronto, na medida certa pra tomar". Há chás para inúmeras queixas, enfermidades e intenções, entre eles, chás para fins abortivos e de

\footnotetext{
${ }^{5}$ De modo geral, todas as aldeias do Alto Xingu têm rádio que permite a comunicação da comunidade com os postos da FUNAI, onde residem equipes médicas que atendem as regiões do Parque do Xingu.
} 
parturição: "usa muito aqui. Minha prima já abortou muitas vezes, ela é solteira".

A decisão do aborto é mais comum entre as solteiras, pois segundo as mulheres da aldeia, "as casadas têm que aceitar". Quando descobre a gravidez, a jovem procura a mãe. Diz-se entre as mulheres do grupo que ninguém instrui as meninas sobre gravidez nem contracepção, mas os namoros precisam ser revelados aos pais da moça. Segundo uma mãe:

[...] Hoje em dia não pode escondido porque senão como vou saber quem engravidou ela? Hoje o rapaz tem que aparecer pros pais, só de aparecer a mãe já sabe, já entende. A maioria das moças obedece os pais quando eles não aceitam o namorado. Tem muito rapaz que só quer saber de namorar, sexo, depois foge da gravidez e diz 'não é meu'.

As mães ouvidas dizem que o sexo é muito comum nos namoros hoje em dia e a preocupação é saber com quem os filhos estão se relacionando. Segundo informantes, há métodos contraceptivos disponíveis na aldeia como uso de chás tradicionais que, segundo elas, estão em desuso e a entrada lenta e progressiva de métodos ocidentais como a camisinha que, ainda segundo as informantes, sofre grande resistência feminina. Em caso de gravidez, quando não há a perspectiva de casamento ${ }^{6}$ o abortamento surge como a opção mais viável.

Culturalmente, diz-se frequentemente entre o povo estudado que é necessário que o pai da criança mantenha relações sexuais com a gestante para auxiliá-la na formação do bebê, sendo que o pai auxilia a formação das partes duras, como ossos e órgãos mais rígidos, e a mãe, através do seu sangue, colabora com a formação

\footnotetext{
6 Tradicionalmente, o casamento é um arranjo articulado pelas famílias e geralmente é expresso simbolicamente pelo gesto da mãe da moça ao buscar a rede do rapaz na casa de seus pais e trazê-la para junto da rede da filha, em sinal de aprovação do laço. Atualmente, diz-se que os próprios jovens escolhem seus parceiros e assume-se um casamento quando eles passam a dormir juntos na casa um do outro.
} 
do sangue do bebê e partes "moles" como cartilagens e órgãos mais delicados.

Nesta perspectiva, o casamento é uma espécie de condição e garantia do desenvolvimento ideal do bebê, razão pela qual é desaconselhável a continuidade da gestação entre meninas solteiras ou em caso de adultério. Há ainda outras razões que levam à decisão de interromper a gravidez e este certamente não é um processo simples, mas não é pretensão deste artigo discorrer sobre este processo de decisão, que engloba uma série de questões de ordem cultural e religiosa que ultrapassam a intenção e o alcance desta pesquisa.

Segundo informações coletadas entre as mulheres do grupo, o abortamento passa por algumas etapas. Num primeiro momento, a moça toma um chá pouco concentrado, depois passa a tomar um chá um pouco mais forte e na terceira etapa o chá é bem forte e amargo. "Dá até dor de cabeça", diz uma mulher que revela ter passado por isso. Nesse período, sugere-se que a mulher não coma nada para que a erva faça efeito. Há outro chá para acelerar as contrações e o nascimento do bebê, utilizado para acelerar o trabalho de parto.

As receitas dos chás são secretas, compartilhadas apenas entre as raizeiras, o que assinala não somente a restrição do conhecimento no interior de um grupo simbolicamente estabelecido como também assegura o envolvimento e a participação destas mulheres em eventos relativos à saúde e ao bem-estar da comunidade. Isso nos revela um aparato de controle e vigilância deste estado físico e espiritual pelo qual a gestante e todo o grupo estão passando.

\section{Considerações Finais}

A fecundidade é considerada a principal responsável pela recuperação demográfica observada entre muitas populações indígenas no Brasil e na América Latina, sendo fruto de estruturas socioculturais específicas. Entre os alto-xinguanos, a organização social tem importante influência sobre o comportamento repro- 
dutivo, cabendo à mulher adulta casar-se e gerar filhos, tendo seu respeito e sua autoridade intimamente relacionados ao tamanho de sua prole e descendência.

Regras, práticas, tabus, processos rituais e mitos relacionados ao nascimento, ao casamento e à reprodução evidenciam a autonomia que os povos indígenas têm sobre sua história reprodutiva, conduzindo suas populações para um tamanho determinado sobre o qual exercem um importante - embora não absoluto - controle, contradizendo argumentos neomalthusianos que consideravam o elevado crescimento dos povos indígenas um acontecimento alheio à vontade destes povos, caracterizando-se como um empecilho para sua sobrevivência (PAGLIARO, 2002b). Ademais, os cuidados, tabus e mitos que circundam os eventos relacionados ao nascer, crescer, amadurecer, casar, gestar, parir e morrer são tecidos minuciosamente por uma complexa rede de relações, conhecimentos e práticas de ordem coletiva.

\section{Referências}

AZEVEDO, M. M. A. Demografia dos povos indígenas do alto rio Negro/AM: um estudo de caso de nupcialidade e reprodução. Tese de doutorado em Demografia. Universidade Estadual de Campinas (UNICAMP). Campinas, 2003.

AZEVEDO, M. M. A. Povos Indígenas na América Latina estão em processo de crescimento. In: INSTITUTO SOCIOAMBIENTAL. Povos Indígenas no Brasil 2001/2005. ISA, 2006.

BRANDÃO, C. R. (Org.). Repensando a pesquisa participante. São Paulo: Ed. Brasiliense, 1984.

CALDWELL, J. Population growth and socioeconomic change in West Africa. Columbia University Press, Population Council, 1975.

CHESNAIS, J. C. The Demographic Transition: Stages, Patterns, and Economic Implications. New York: Claredon Press, Oxford University Press, 1992. 
ERVITTI DIAZ, B. População e desenvolvimento. Centro de Estudos Demográficos (CEDEM). Cuba, 1998.

GOLDANI, A. M. Estrutura familiar e transição demográfica: o caso do Brasil. Informe Demográfico, v. 17, São Paulo, 1985.

GUZMÁN, J. M. et al. The demography of Latin America and the Caribbean since 1950. Population-E, v. 61, n. 5, p. 519-620, 2006.

LOPEZ, G. M. A. A fecundidade entre os Guarani: um legado de Kunhankarai. Tese de doutorado em Ciências na área de Saúde Pública. Fundação Oswaldo Cruz. Escola Nacional de Saúde Pública. Rio de Janeiro, 2000.

LANDRY, A. La Révolution Démographique. Etudes et Essais sur les problèmes de la Population. Paris: Ined, 1982 (Reedição da publicação de 1934).

LORIMER, F. Culture and Human Fertility. New York: Greenwood Press, 1958.

MALINOWSKI, B. Objetivo, método e alcance desta pesquisa. In. Desvendando máscaras sociais. Rio de Janeiro: Francisco Alves, 1990, 3aㅡ edição.

NOTESTEIN, F. Population: the long view. In. SCHULTZ, T. W. (Ed.). Food for the world. Chicago: University of Chicago Press, 1945.

PAGLIARO, H. A revolução demográfica dos povos indígenas do Brasil: a experiência dos Kaiabi do Parque Indígena do Xingu, Mato Grosso, 1970-1999. Tese de doutorado em Epidemiologia. Faculdade de Saúde Pública da Universidade de São Paulo (USP). São Paulo, 2002a.

PAGLIARO, H. A Recuperação Demográfica dos Povos Indígenas do Brasil: a experiência dos Kaiabi do Parque Indígena do Xingu - Mato Grosso. XIII Encontro da Associação Brasileira de Estudos Populacionais. Anais... ABEP, 2002b. 
PAGLIARO, H. et al. Comportamento Demográfico dos Índios Kamaiurá, Parque Indígena do Xingu, Mato Grosso, Brasil (1970-1999). XIV Encontro Nacional de Estudos Populacionais. Anais... ABEP, 2004.

PATARRA, N. L.; FERREIRA, C. E. C. Repensando a Transição Demográfica: formulações, críticas e perspectivas de análise. Campinas: NEPO/UNICAMP, outubro de 1986.

PATARRA, N. L.; OLIVEIRA, M. C. F. A. Transição, Transições. IV Encontro Nacional de Estudos Populacionais. Anais... ABEP, 1988.

RIBEIRO, D. Convívio e contaminação. Efeitos dissociativos da depopulação provocada por epidemias em grupos indígenas. Revista Sociologia, São Paulo, v.18, n. 1, 1956.

RIBEIRO, D. Culturas e línguas indígenas do Brasil. In: Educação e Ciências Sociais, Rio de Janeiro, v. 2, n. 6, 1957.

SANTOS, J. L. F. et al. Dinâmica da população: teoria, métodos e técnicas de análise. São Paulo: T. A. Queiroz, 1980.

SHORTER, B. A obscura formação de uma imagem: mulheres e iniciação. Rio de Janeiro: Paz e Terra, 1989.

SOUZA, L. G. Demografia e Saúde dos Índios Xavante do Brasil Central. Tese de doutorado. Escola Nacional de Saúde Pública (ENSP)/ Fiocruz. Rio de Janeiro, 2008.

THOMPSON, W. S. Population. American Journal of Sociology, 1929.

TURNER, V. W. O processo ritual: estrutura e antiestrutura. Petrópolis: Vozes, 1974.

VAN GENNEP, A. Os ritos de passagem. Petrópolis: Vozes, 1977.

VIVEIROS DE CASTRO, E. B. A fabricação do corpo na sociedade xinguana. In. OLIVEIRA FILHO, João Pacheco de. (Org.) Sociedades indígenas e indigenismo no Brasil. Rio de Janeiro: Ed. Marco Zero, 1987. 
| 252 |

Comportamento reprodutivo...

ZUBROW, E. B. W. Demographic anthropology: an introductory analysis. In.ZUBROW, E. B. W.(Ed.). Demographicanthropology. Santa Fé: School of American Research, 1976. 